\title{
$\lg A$ and $\lg G$ antibody detection of mycobacterial antigens in pleural fluid and serum from pleural tuberculous patients
}

\author{
Renan Jeremias da Silva ${ }^{1}$, Raquel da Silva Corrêa ${ }^{2}$, Isabela Gama Sardella ${ }^{1}$, Ana Carla de Paulo Mulinari ${ }^{1}$, \\ Thiago Thomaz Mafort ${ }^{3}$, Ana Paula Santos ${ }^{3}$, Rogério Rufino ${ }^{3}$, Luciana Silva Rodrigues ${ }^{2}$ and \\ Maria Helena Féres Saad ${ }^{1 *}$ (D)
}

\begin{abstract}
Background: A previous study demonstrated pleural fluid (PF) IgA immunodominance for the fused MT10.3:MPT64 protein in pleural tuberculosis (PLTB) cases. However, no clue on the role of IgA and IgG against this and other antigens in PF and serum concerning improved diagnosis is available. Thus, the aim of the present study was to validate PF IgA-MT10.3:MPT64 and evaluate PF and serum IgA and IgG reactivity against this protein, its peptides (F2) and single MPT64, MT10.3 and the PPE59 mycobacterial specific antigens. IgA and IgG ELISA were measured against the antigen in PLTB $(n=29)$ and other non-TB pleurisy $(n=39)$ patient samples.

Results: The immunodominance of PF IgA-MT10.3:MPT64 was confirmed in PLTB (86.2\%) followed by PPE59 (62\%), while serum IgA-F2 exhibited 51.7\% sensitivity. PF and serum IgG-MT10.3:MPT64 led to 65.5 and $51.7 \%$ sensitivity, respectively. However, MT10.3 and MPT64 displayed overall lower sensitivity $(\leq 34.5)$ for both antibodies. All results at 95\% fixed specificity. Combinatory results indicated 93.1\% sensitivity for PF IgA-MT10.3:MPT64/-PPE59 and IgA/ IgG-MT10.3:MPT64 at 92.3\% specificity, followed by IgA-MT10.3:MPT64/-MPT64 or /-F2 (89.6\%) without jeopardizing specificity (94.9\%). The combinatory results of the PF adenosine deaminase test (ADA) and IgA-MT10.3:MPT64/-F2 demonstrated the highest sensitivity (96.6\%), with a specificity of $92.3 \%$.

Conclusions: The PF IgA-MT10:MPT64 immune dominance was validated in PLTB, and its combinatory results with PPE59 or MPT64 or F2 antigens as well as with IgG, are reported herein for the first time, improving their potential to assist diagnosis. Combining PF-ADA and IgA-MT10.3:MPT64/-F2 results achieved better accuracy. Moreover, serum IgG, although less accurate, displays potential beyond microbiological tests.
\end{abstract}

Keywords: Mycobacterium tuberculosis, Pleural tuberculosis, IgA, IgG, ELISA, ADA

\section{Background}

Pulmonary tuberculosis is the most common clinical manifestation of Mycobacterium tuberculosis (MTB) infection. Among extrapulmonary presentations pleural tuberculosis (PLTB) is the most frequent in many countries, representing $15 \%$ of the extrapulmonary cases globally reported in 2016 [1-3]. Moreover, PLTB is the major cause of pleural effusions, responsible for approximately $50 \%$ of all related diagnoses in Brazil $[4,5]$. The

\footnotetext{
* Correspondence: saad@ioc.fiocruz.br

'Laboratorio de Microbiologia Celular, Instituto Oswaldo Cruz (IOC),

Fundação Oswaldo Cruz (FIOCRUZ), Av. Brazil, 4365, Rio de Janeiro

21040-360, Brazil

Full list of author information is available at the end of the article
}

disease generally affects immunocompetent young adults, but, although patients may spontaneously heal, there is a risk of developing active tuberculosis (TB) in the absence of specific drug administration. Thus, early diagnosis and adequate treatment are required to avoid PLTB evolution to tuberculous empyema or pleural fibrosis $[6,7]$.

Microbiological methods depend on the presence of bacilli in clinical specimens, therefore displaying low sensitivity in paucibacilary cases, like PLTB patients. The use of molecular techniques is costly and restricted to centers with adequate structure and specialized professionals. Histopathological examination of pleural biopsy

(c) The Author(s). 2019 Open Access This article is distributed under the terms of the Creative Commons Attribution 4.0 International License (http://creativecommons.org/licenses/by/4.0/), which permits unrestricted use, distribution, and reproduction in any medium, provided you give appropriate credit to the original author(s) and the source, provide a link to the Creative Commons license, and indicate if changes were made. The Creative Commons Public Domain Dedication waiver (http://creativecommons.org/publicdomain/zero/1.0/) applies to the data made available in this article, unless otherwise stated. 
samples comprises the standard PLTB reference test, but exhibits variable sensitivity, is expensive, timeconsuming, requires skilled personnel and an invasive procedure $[8,9]$. Serological tests based on antibodies (Ab) response may be an attractive alternative as a diagnostic method, as they are simple, fast and easy to operate, allowing their application in the public health system, where the diagnostic demand is high. In addition, they are not dependent on the presence of the bacilli in clinical specimens. In a previous study, Araujo et al. [10] demonstrated that the MT10.3:MPT64 fused antigen is recognized by immunoglobulin A (IgA) in the pleural fluid (PF) of PLTB patients, at high sensitivity (81.4\%) and specificity (95.5\%). Furthermore, the cloned fusion protein based on MPT64 and MT10.3 epitopes, termed F2 (MT10.3(1M-40S):MPT64m(91L-205A):MT10.3(41S-96)), was described to be predominantly recognized by serum IgA in pulmonary TB [11]. The PE (Pro-Glu) and PPE (Pro-ProGlu) molecules are coding by two families of genes responsible for about $10 \%$ of the MTB genome [12]. Proteins belonging to PPE family are involved in many aspects of TB pathogenesis, including antibody recognition and bacilli persistence ability in granulomas [13-16]. Moreover, their antigenic variation has been associated with the ability of determined microbial pathogens to evade the immune system [17]. The PPE59 protein coding gene rv3429c belonged the RD11, region absent in $M$. bovis. The actual role of PPE59 in metabolism or in the clinical evolution of MTB infection is not well known, but it is capable of inducing a cell-mediated response by IFN- $\gamma$ and interleukin-10 [13, 15]. However, no clues on the reactivity to these antigens (Ags) by $\mathrm{Ab}$ of PF and/or serum of PLTB cases are available.

On the other hand, the use of adenosine deaminase (ADA) biochemical test may contribute to a more efficient and differential diagnosis in PLTB cases [1, 18-20]. Although it is a fast, cheap, reproducible and an easy to perform assay $[8,9]$, it presents several limitations: the predictive value depends on the local TB prevalence, low sensitivity in immunocompromised patients, falsepositive results due to cross-reactivity with other diseases presenting pleural effusion, such as lymphoma, vascular collagen diseases and bacterial empyema. Furthermore, due a wide range of results from region to region should be used with caution in countries with low TB incidence [21-23]. Therefore, identification of new biomarkers and, consequently, the development of diagnostic test that differentiate PLTB from other pathologies presenting exudative pleural effusion may have a significant impact on primary care. In this context, here we investigated potential PLTB biomarkers, validating and/or evaluating the accuracy of dosing IgA and IgG response to mycobacterial single Ags MT10.3, MPT64 and PPE59, fusion proteins
MT10.3:MPT64 and the novel F2, in PF and sera from patients with pleural effusion using an in-house ELISA method.

\section{Results}

\section{Participant characteristics}

Sixty-eight subjects with pleural effusion were enrolled in this study. As the microbiological testes yielded a low sensitivity and a universal composite reference standard (CRS) for PLTB diagnosis is not available, a CRS based on the clinical history, microbiological, radiological, and biochemical findings associated with PLTB based on recently published literature [24] was used by HUPE health professionals for final diagnosis [25]. The patients were classified into 2 categories, 29 (42.6\%) PLTB and 39 (57.4\%) with other non-tuberculous pleurisy (OPL) (Fig. 1).

The main clinical, laboratory, and epidemiological data are depicted in Additional file 1: Table S1. Subjects differ in age, as OPL patients were older $(p<0.001)$ and the cancer pathology was dominant (64.1\%), male gender was the majority of PLTB (72.5\%), although no significant difference compared to OPL was observed ( $p=$ $0.12)$. Few participants reported past TB treatment (4/ $68,5.8 \%$ ), including two OPL patients. Concerning patients whose samples underwent conventional and ADA diagnostic tests, the PF-ADA investigation elicited adequate sensitivity and high specificity $(79.3 \%, 23 / 29$ and $94.9 \%, 37 / 39$ ), followed by pleural biopsy histopathology suggestive of TB $(69.2 \%, 9 / 13$ and $76.2 \%, 16 / 21)$, respectively. Lower sensitivity and high specificity were obtained for the pleural biopsy $(25 \%, 1 / 5$ and $100 \%, 3 / 3)$ and PF culture $(14.3 \%, 4 / 28$ and $100 \%, 36 / 36)$ and acidfast bacilli (AFB) smears $(0 \%, 0 / 28$ and $100 \%, 35 / 35)$, respectively (Fig. 2).

\section{Test results \\ Pleural fluid and serum IgA and IgG antibodies against MT10.3:MPT64, F2, PPE59, MT10.3 and MPT64}

All enrolled participants had ELISA serum and PF examined for specific $\mathrm{Ab}$ in response to the five proposed antigens. The significantly high mean levels in PLTB compared to OPL for all $\mathrm{Ab}$ and antigens $(p \leq 0.031)$, except IgG (MPT64, PPE59 and F2) and IgA (MT10.3), at different sera dilutions $(p \geq 0.057)$, are displayed in Fig. 3a and b. Different samples dilutions were considered to evaluate whether results from different dilutions favored sensitivity without altering the specificity of the ELISA test. According to the receiver operating characteristic (ROC) curve analysis, when fixing specificity at 95\%, a high positivity of PF IgA-MT10.3:MPT64 was confirmed registering the best sensitivities at 1:50 and 1:200 specimen dilutions $(86.2 \%)$, followed by $82.8 \%$, at $1: 400$. PF IgA-PPE59 (62.1\%) and -F2 (44.8\%) elicited moderate 


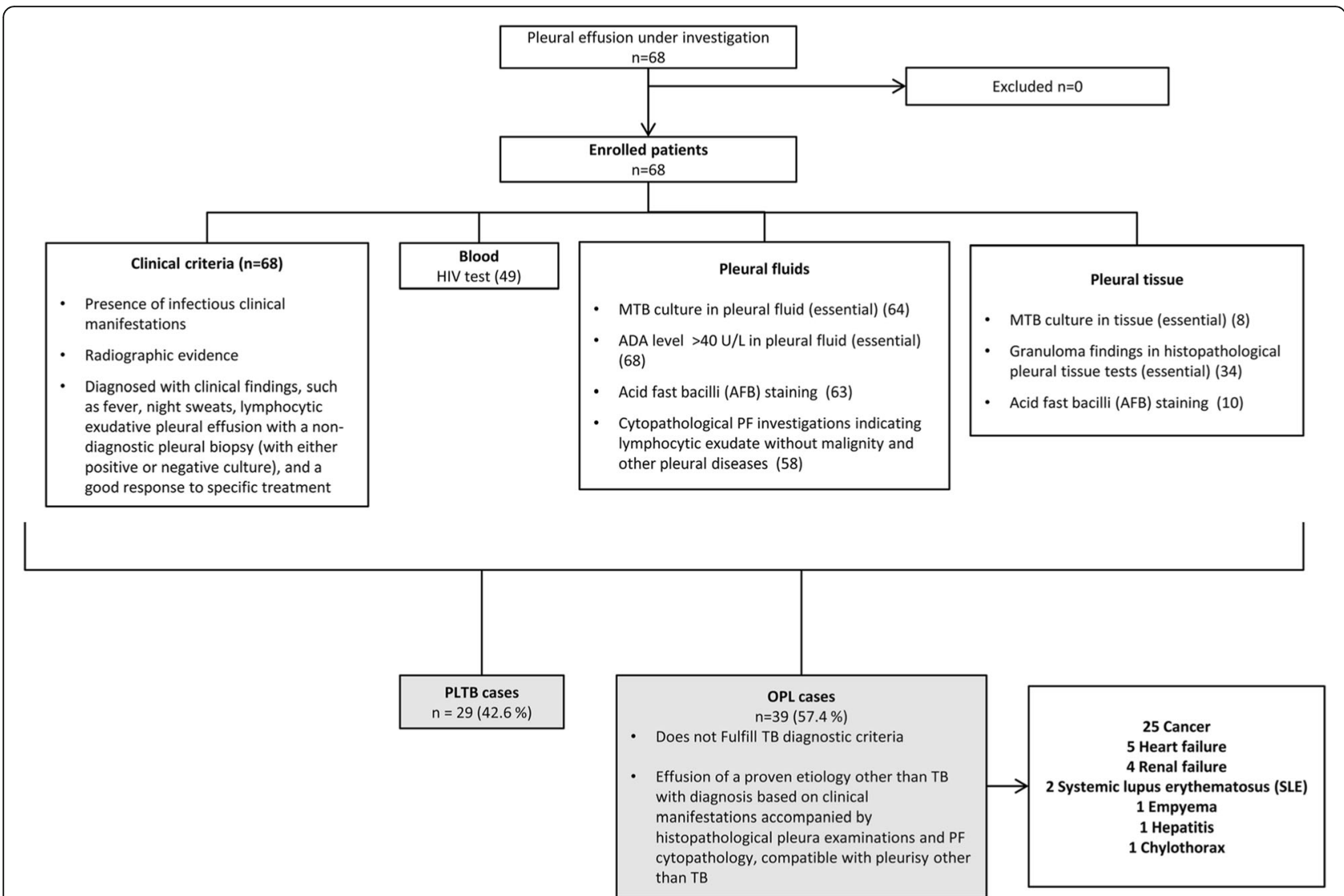

Fig. 1 Flow chart of the study design, classification of study participants and diagnostic testing performed. Composite reference standard (CRS) used for categorization of study participants. AFB: acid-fast bacilli; ADA: adenosine deaminase; PLTB: Pleural tuberculosis. Round blankets: numbers refer to the patients submitted to the correspondent diagnostic test. Gray boxes show the final diagnosis and the study groups

and low sensitivities at 1:100 and 1:50 dilutions, respectively. All tests showed AUC >0.904, except for F2. Serum IgA-F2 reached the best positivity (51.7\%) at both 1:25 and 1:50 dilutions and AUC $<0.844$. For IgG, the only antigen recognized by PLTB patients with high AUC (0.952) was the MT10.3:MPT64, with sensitivity of $65.5 \%$ in PF at a 1:200 dilution, decreasing to $51.7 \%$ in serum at a 1:50 dilution and AUC $=0.809$ (Table 1 and Fig. 4).

It is noteworthy that, when combining the PF IgAMT10.3:MPT64 (1:50) -MPT64 (1:100) or -F2 (1:50), or IgA-MT10.3:MPT64/-PPE59 (1:200/1:100, respectively) results, sensitivity improved to $89.6 \%$ without jeopardizing specificity (94.9\%). These results were not obtained for any other tested Ags, although PF IgA-MT10.3: MPT64/-PPE59 (1:50/1:100) and IgA/IgG- MT10.3: MPT64 combinatory results elicited the highest sensitivity $(93.1 \%)$, indicating a slight decrease in specificity (92.3\%), while serum IgG (1:50/1:800 or $1: 1600)$ led to the best combination result $(55.1 \%)$ for both fusion proteins MT10.3:MPT64/F2, with the same specificity (Table 2). Other IgA and/or IgG antigen combinatory results have reached moderate to high sensitivities (> $68 \%)$, however, jeopardizing specificity (89.7\%).
The cross reactivity was observed in only two OPL patient for PF at 1:50 dilution associated to both, IgAMT10.3:MPT64 and IgA-F2 (Fig. 5), being diagnosed with cancer and heart failure, respectively. The patient with cancer presented negative results for PF-ADA and pleural biopsy histopathology. The patient with heart failure showed negative results for PF-ADA and AFB staining tests, histopathological examination was not done. However, one this patient tested positive for the QuantiFERON ${ }^{\bullet}$-TB Gold In-Tube (QFT-GIT) assay (data not shown). These results may suggest latent tuberculosis infection (LTBI).

\section{Comparison of standard conventional tests and ADA assay with the ELISA in pleural tuberculosis diagnoses}

Considering the best results for PF or serum IgG and IgA with different antigens, we hypothesized if they were more accurate in comparison with other tests used to diagnosis PLTB. As depicted in Fig. 5, PF-ADA ( $\mathrm{S}=$ $79.3 \%$ and $\mathrm{Sp}=94.9 \%$ ) or pleural biopsy histopathology $(\mathrm{S}=69.2 \%, 9 / 13$ and $\mathrm{Sp}=76.2 \%, 16 / 21)$ were less accurate than PF IgA-MT10.3:MPT64 (1:50) and its combinatory results with /MPT64 (1:100) or /F2 (1:50), which 


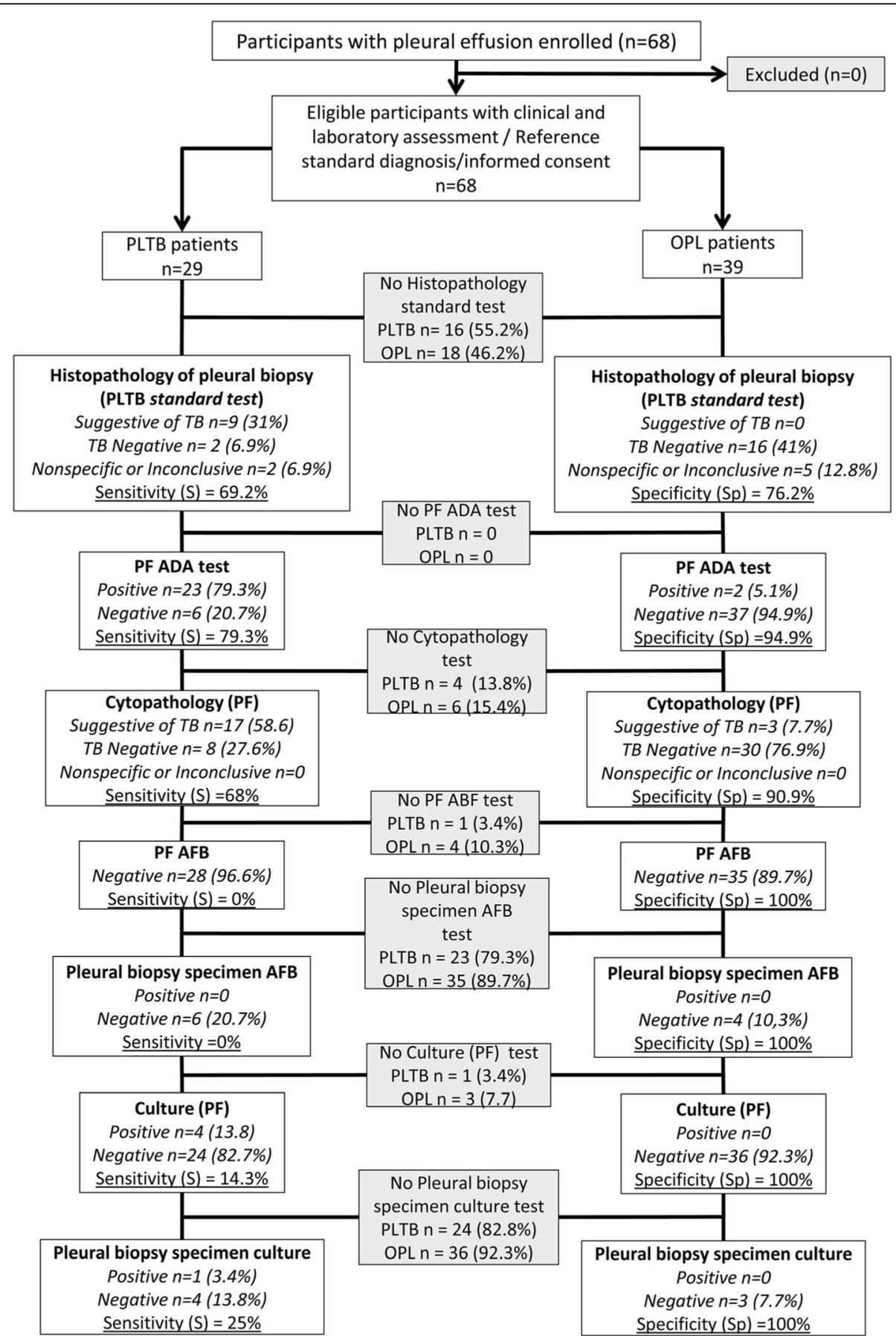

Fig. 2 Standards for reporting of diagnostic accuracy (STARD) flow diagram showing the conventional microbiological, histopathological and adenosine deaminase (ADA) tests determined in pleural fluid (PF) and/or pleural biopsy (PB) samples for tuberculous pleural infection (PLTB) diagnosis

elicited $\mathrm{S} \geq 89.6 \%$ and $\mathrm{Sp}=94.9 \%$. Thus, PF-IgA ELISA produced better positivity to that conventional testing, but the ELISA positivity among negative results provided by those conventional tests in PLTB is noteworthy. Although histopathologic examination was not done for all patients, $15.3 \%$ were non-specific but positively identified by the ELISA, which positively also detected PLTB cases without known histopathological exam (12/ 16, 75\%). Thus, the ELISA resulted in an overall sensitivity of $86.2 \%$, against $69.2 \%$ of the histopathological exam. On the other hand, most of the PLTB cases with negative ADA resulted in positive PF IgA-MT10.3:MPT64 
a

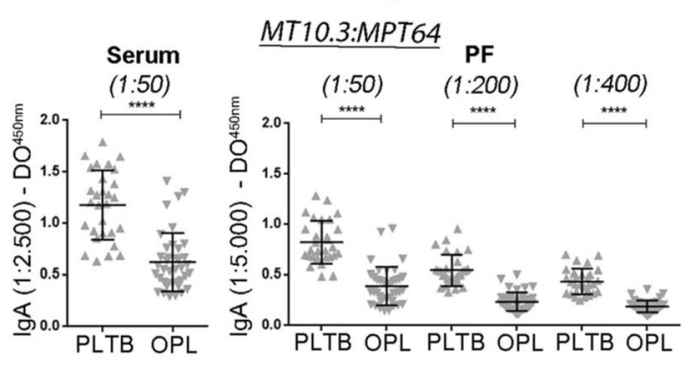

$\underline{F 2}$
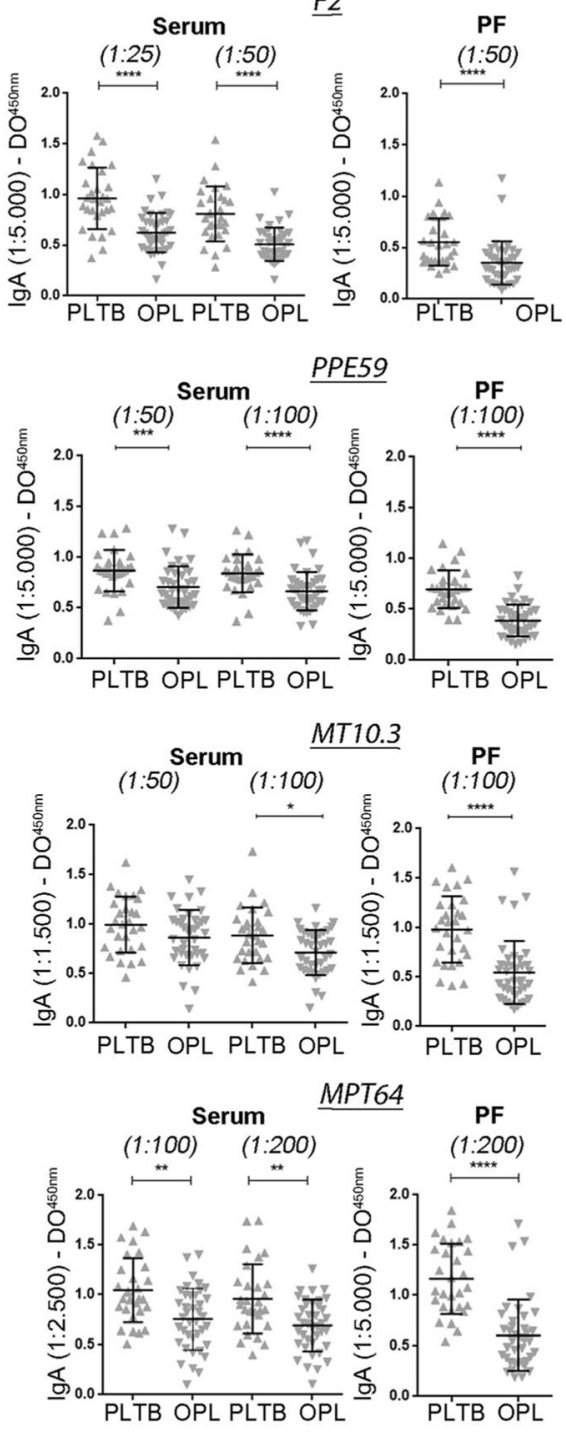

$b$
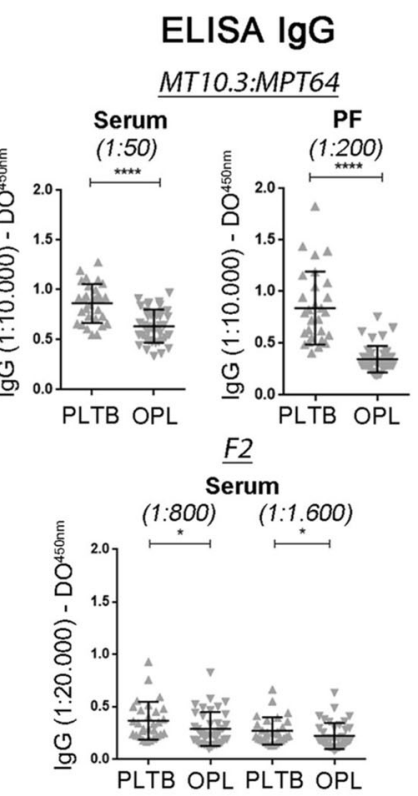

$\underline{P P E 59}$

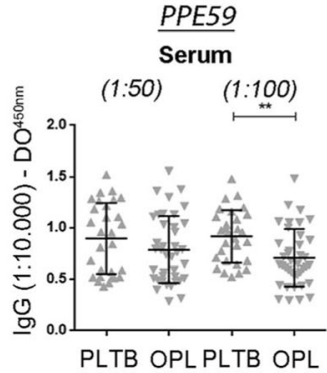

MT10.3

Serum

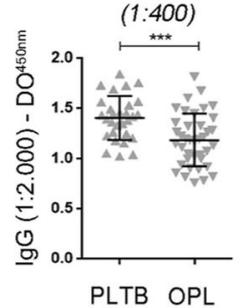

MPT64

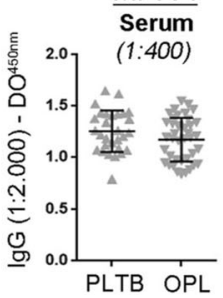

Fig. 3 Distribution of individual humoral responses of (a) IgA and (b) lgG antibodies against different mycobacterial Ag, MT10.3, MPT64, PPE59, the MT10.3:MPT64 and the F2 fusion protein, in different dilutions of pleural fluid (PF) and serum of patients with pleural tuberculosis (PLTB) or other pleurisy non-TB (OPL). Note: Short bars, mean ODs. ${ }^{* * *}, p \leq 0.0001,{ }^{* * *}, p \leq 0.0009 ;{ }^{* *}, p \leq<0.001 ;{ }^{*}, p \leq 0.05$

diluted at 1:50 (5/6), as well as their combinatory results with /MPT64 (1:100) or /F2 (1:50) (5/6, respectively). Moreover, microbiological tests also not done in all samples, performed weaker $(>25 \%)$, as expected in paucibacilary cases, such as PLTB. However, the ELISA proposed herein provided significantly better detection (ranging from 51.7 to $89.6 \%$ ) for IgG or IgA determined in serum $(51.7 \%$ or $44.8 \%)$ or PF $(65.5 \%$ or $>86 \%$, 
Table 1 ELISA validity parameters for the detection of IgA and IgG antibodies against mycobacterial antigens MT10.3, MPT64, PPE59, and the MT10.3:MPT64 and the F2 fusion proteins, at different pleural fluid (PF) and serum dilutions

\begin{tabular}{|c|c|c|c|c|c|c|c|}
\hline \multirow{2}{*}{$\begin{array}{l}\text { ELISA tests (samples } \\
\text { dilutions) }\end{array}$} & PL-TB $(n=29)$ & OPL $(n=39)$ & \multirow{2}{*}{$\begin{array}{l}\mathrm{p} \\
\text { valor }^{\mathrm{a}}\end{array}$} & \multirow{2}{*}{$\begin{array}{l}\text { Cut } \\
\text { off }\end{array}$} & \multirow[t]{2}{*}{ AUC } & \multirow{2}{*}{$\begin{array}{l}\text { Sensitivity (\%) } \\
\text { (Number of }+ \text { ) }\end{array}$} & \multirow{2}{*}{$\begin{array}{l}\text { Specificity (\%) } \\
\text { (Number of -) }\end{array}$} \\
\hline & Mean \pm SD & Mean \pm SD & & & & & \\
\hline \multicolumn{8}{|l|}{$\lg A-(P F)$} \\
\hline MT10.3 (1:100) & $0.983 \pm 0.336$ & $0.548 \pm 0.321$ & * & 1.278 & 0.852 & $20.7(6)$ & $95(37)$ \\
\hline MPT64 (1:100) & $1.164 \pm 0.350$ & $0.606 \pm 0.352$ & * & 1.505 & 0.887 & $24.1(7)$ & $95(37)$ \\
\hline MT10.3-MPT64 (1:50) & $0.821 \pm 0.213$ & $0.387 \pm 0.188$ & * & 0.658 & 0.949 & $86.2(25)$ & $95(37)$ \\
\hline MT10.3-MPT64 (1:100) & $0.667 \pm 0.195$ & $0.302 \pm 0.138$ & * & 0.598 & 0.950 & $65.5(19)$ & $95(37)$ \\
\hline MT10.3-MPT64 (1:200) & $0.542 \pm 0.154$ & $0.232 \pm 0.093$ & * & 0.385 & 0.968 & $86.2(25)$ & $95(37)$ \\
\hline MT10.3-MPT64 (1:400) & $0.433 \pm 0.126$ & $0.185 \pm 0.060$ & * & 0.315 & 0.980 & $82.8(24)$ & $95(37)$ \\
\hline MT10.3-MPT64 (1:800) & $0.323 \pm 0.125$ & $0.209 \pm 0.094$ & * & 0.404 & 0.823 & $27.6(8)$ & $95(37)$ \\
\hline PPE59 (1:100) & $0.696 \pm 0.186$ & $0.392 \pm 0.155$ & * & 0.639 & 0.904 & $62.1(18)$ & $95(37)$ \\
\hline F2 (1:50) & $0.553 \pm 0.230$ & $0.351 \pm 0.212$ & * & 0.542 & 0.774 & $44.8(13)$ & $95(37)$ \\
\hline \multicolumn{8}{|l|}{$\lg A-($ serum) } \\
\hline MT10.3 (1:50) & $0.996 \pm 0.282$ & $0.865 \pm 0.279$ & 0.081 & 1.282 & 0.625 & $20.7(6)$ & $95(37)$ \\
\hline MT10.3 (1:100) & $0.888 \pm 0.281$ & $0.714 \pm 0.228$ & 0.012 & 1.018 & 0.678 & $27.6(8)$ & $95(37)$ \\
\hline MT10.3 (1:200) & $0.760 \pm 0.263$ & $0.634 \pm 0.209$ & 0.057 & 0.962 & 0.636 & $13.8(4)$ & $95(37)$ \\
\hline MT10.3 (1:400) & $0.622 \pm 0.216$ & $0.528 \pm 0.172$ & 0.130 & 0.799 & 0.608 & $13.8(4)$ & $95(37)$ \\
\hline MPT64 (1:50) & $1.109 \pm 0.341$ & $0.843 \pm 0.371$ & 0.003 & 1.462 & 0.708 & $20.7(6)$ & $95(37)$ \\
\hline MPT64 (1:100) & $1.045 \pm 0.323$ & $0.757 \pm 0.308$ & * & 1.220 & 0.729 & $27.6(8)$ & $95(37)$ \\
\hline MPT64 (1:200) & $0.959 \pm 0.347$ & $0.693 \pm 0.258$ & 0.002 & 1.048 & 0.717 & $34.5(10)$ & $95(37)$ \\
\hline MPT64 (1:400) & $0.860 \pm 0.338$ & $0.630 \pm 0.231$ & 0.006 & 1.012 & 0.695 & $27.6(8)$ & $95(37)$ \\
\hline MT10.3:MPT64 (1:50) & $1.176 \pm 0.338$ & $0.621 \pm 0.282$ & * & 1.267 & 0.905 & $44.8(13)$ & $95(37)$ \\
\hline PPE59 (1:50) & $0.868 \pm 0.204$ & $0.706 \pm 0.206$ & * & 1.042 & 0.736 & $13.8(4)$ & $95(37)$ \\
\hline PPE59 (1:100) & $0.841 \pm 0.189$ & $0.663 \pm 0.190$ & * & 1.043 & 0.785 & $13.8(4)$ & $95(37)$ \\
\hline F2 (1:25) & $0.963 \pm 0.304$ & $0.624 \pm 0.195$ & * & 0,957 & 0.837 & $51.7(15)$ & $95(37)$ \\
\hline F2 (1:50) & $0.810 \pm 0.271$ & $0.507 \pm 0.165$ & * & 0,772 & 0.844 & $51.7(15)$ & $95(37)$ \\
\hline F2 (1:100) & $0.698 \pm 0.282$ & $0.414 \pm 0.134$ & * & 0,670 & 0.847 & $48.3(14)$ & $95(37)$ \\
\hline F2 (1:200) & $0.619 \pm 0.252$ & $0.443 \pm 0.188$ & * & 0,591 & 0.879 & $44.8(13)$ & $95(37)$ \\
\hline \multicolumn{8}{|l|}{$\operatorname{lgG}-(\mathrm{PF})$} \\
\hline MT10.3-MPT64 (1:200) & $0.840 \pm 0.352$ & $0.347 \pm 0.126$ & * & 0.616 & 0.952 & $65.5(19)$ & $95(37)$ \\
\hline \multicolumn{8}{|l|}{ IgG-(serum) } \\
\hline MT10.3:MPT64 (1:50) & $0.863 \pm 0.196$ & $0.636 \pm 0.195$ & * & 0.891 & 0.809 & $51.7(15)$ & $95(37)$ \\
\hline MT10.3 (1:400) & $1.409 \pm 0.218$ & $1.190 \pm 0.261$ & * & 1.641 & 0.739 & $17.2(5)$ & $95(37)$ \\
\hline MPT64 (1:400) & $1.256 \pm 0.201$ & $1.173 \pm 0.213$ & 0.129 & 1.490 & 0.609 & $10.3(3)$ & $95(37)$ \\
\hline PPE59 (1:50) & $0.918 \pm 0.252$ & $0.789 \pm 0.327$ & 0.204 & 1.370 & 0.591 & $3.4(1)$ & $95(37)$ \\
\hline PPE59 (1:100) & $0.898 \pm 0.346$ & $0.709 \pm 0.279$ & 0.003 & 1.181 & 0.711 & $17.2(5)$ & $95(37)$ \\
\hline F2 $(1: 200)$ & $0.604 \pm 0.319$ & $0.499 \pm 0.313$ & 0.087 & 1.084 & 0.622 & $6.9(2)$ & $95(37)$ \\
\hline F2 (1400) & $0.467 \pm 0.267$ & $0.387 \pm 0.232$ & 0.127 & 0.787 & 0.609 & $10.3(3)$ & $95(37)$ \\
\hline F2 $(1: 800)$ & $0.369 \pm 0.180$ & $0.289 \pm 0.161$ & 0.024 & 0.552 & 0.660 & $13.8(4)$ & $95(37)$ \\
\hline F2 (1:1600) & $0.271 \pm 0.127$ & $0.223 \pm 0.123$ & 0.031 & 0.427 & 0.663 & $10.3(3)$ & $95(37)$ \\
\hline
\end{tabular}

$\lg A$ and $\lg G$ mean level results in optical density and their standard deviations (SD)

PLTB pleural tuberculosis patients, OPL patients with other, non-TB, pleural diseases, AUC area under the curve

${ }^{\mathrm{a} S}$ Significant difference of $\lg \mathrm{A} / \mathrm{lgG}$ production between groups and between tested antigen were calculated by the Mann Whitney test $\left(p<0.001^{*}\right)$ Boldface: represents the antigens tests of best sensitivities 

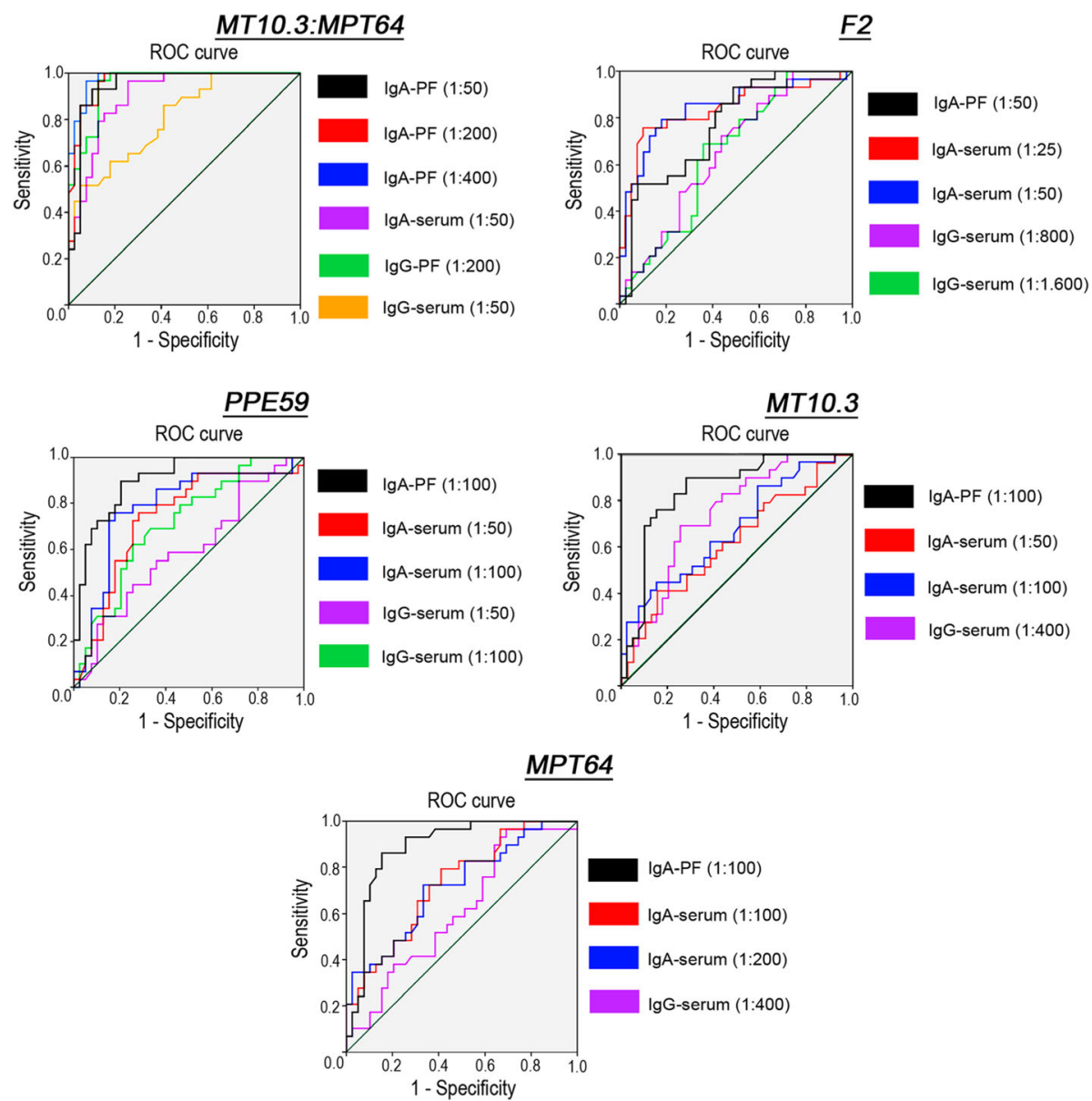

Fig. 4 ROC curve of the IgA and IgG antibodies against different mycobacterial Ag, MT10.3, MPT64, PPE59, the MT10.3:MPT64 and the F2 fusion proteins, at different dilutions of pleural fluid (PF) and serum of patients with pleural tuberculosis (PLTB) or other pleurisy non-TB (OPL)

respectively), especially for the combinatory PF (1:50) IgAMT10.3:MPT64/F2 results (Table 2, Fig. 5). None of the other combinatory results led to better accuracy.

One of the disadvantages of the immune humoral test is the $\mathrm{Ab}$ response heterogeneity across patients [2628]. As the present study evaluated a small number of antigens or their fused peptides, some of the patients did not respond. Thus, we evaluate the ELISA combined with ADA results, as both tests were performed for all samples, aiming at diagnostic improvement. The combined results of PF (1:50) IgA-MT10.3-MPT64/-F2 and ADA provided the best sensitivity $(96.6 \%, 28 / 29)$ for PLTB detection, at $92.3 \%$ specificity (36/39) (Table 2).

\section{Discussion}

Simple, fast and accurate diagnostic methods in PLTB are still required. For instance, the reference histopathological examination for pleural biopsy was virtually not performed in the present sampling as compared to Araújo et al [10]. On the contrary, the diagnosis herein relied on clinical suspicion and the simple ADA test for all patients, reaching 79\% sensitivity. However, PF IgA MT10.3:MPT64 (86.2\%) and it combined results with /-MPT64 or /-F2 identified all, except one, PLTB negative ADA, and, despite missing three or two of the positive ADA PLTB patients, the ELISA improved pleurisy tuberculosis detection $(89.6 \%)$. The combinatory results for PF (1:50) IgA MT10.3:MPT64/-F2 and ADA displays a double advantage, as, besides increasing sensitivity (96.6\%), the PF can be used at the same dilution for both fused Ags when compared to the combinatory results of different PF dilutions used to obtain the same high sensitivity, thus making them suitable as a diagnosis test to aid in PLTB diagnosis. Moreover, the combinations of tests results can obviate the need for a pleural biopsy during the initial diagnostic and, as the ELISA and ADA are fast techniques and of low costs, easy to operate and to apply in public health systems, they favor a rapid auxiliary PLTB diagnosis. Recently, authors have suggested the use of ADA in combination with other diagnostic tests, such as interferon-gamma (IFN- $\gamma$ ) release assays, and in the search for new biomarkers [18-20, 29-32]. 
Table 2 lgA and/or IgG MT10.3:MPT64 Pleural Fluid (PF) and/or sera dilutions combination results with other antigens or ADA results that provide the best sensibility (S) and specificity (Sp) for pleural tuberculosis patients (PLTB)

\begin{tabular}{|c|c|c|}
\hline MT10.3:MPT64 Combination results (sample dilutions)/ & $\begin{array}{l}\text { PLTB }(N=29) \\
\text { N. Positive } \\
\text { S (\%) }\end{array}$ & $\begin{array}{l}\text { OPL }(N=39) \\
\text { N. Negative } \\
\text { Sp (\%) }\end{array}$ \\
\hline \multicolumn{3}{|l|}{ Pleural Fluid IgA } \\
\hline (1:50) / PPE59 (1:100) & $27(93.1)$ & $36(92.3)$ \\
\hline$(1: 100) /$ PPE59 (1: 100) & $24(82.7)$ & $37(94.8)$ \\
\hline (1:200) / PPE59 (1:100); & $26(89.6)$ & $37(94.8)$ \\
\hline \multicolumn{3}{|l|}{ (1:50) / MPT64 (1:100); } \\
\hline \multicolumn{3}{|l|}{$(1: 50) / F 2(1: 50)$} \\
\hline$(1: 400) /$ PPE59 (1:100); & $26(89.6)$ & $36(92.3)$ \\
\hline \multicolumn{3}{|l|}{$(1: 50)$ or /(1:200) or /(1:400) / MT10.3 (1:100) } \\
\hline$(1: 800)$ / PPE59 (1:100); & $21(72.4)$ & $36(92.3)$ \\
\hline \multicolumn{3}{|l|}{$(1: 100) /$ MT10.3 (1:100) } \\
\hline$(1: 100)$ / MPT64 (1:100) & $20(68.9)$ & $36(92.3)$ \\
\hline (1:200) / MPT64 (1:100) or / F2 (1:50) or / MT10.3:MPT64.serum1.50 & $25(86.2)$ & $36(92.3)$ \\
\hline$(1: 400)$ / MPT64 (1:100) or / F2 (1:50) & $24(82.7)$ & $36(92.3)$ \\
\hline$(1: 100) / F 2(1: 50)$ & $22(75.8)$ & $36(92.3)$ \\
\hline (1:50) / MT10.3-MPT64.serum1.50 & $26(93.1)$ & $35(89.7)$ \\
\hline (1:1000) / MT10.3-MPT64.serum1.50 & $19(65.5)$ & $36(92.3)$ \\
\hline \multicolumn{3}{|l|}{ Serum $\lg A$} \\
\hline (1.50) / MPT64 (1:50) & $13(44.8)$ & $36(92.3)$ \\
\hline (1.50) / MPT64 (1:200) & $14(48.2)$ & $36(92.3)$ \\
\hline \multicolumn{3}{|l|}{ Serum lgG } \\
\hline$(1: 50) / F 2(1: 400)$ & $15(51.7)$ & $36(92.3)$ \\
\hline$(1: 50) / F 2(1: 800$ or $1: 1600)$ & $16(55.1)$ & $36(92.3)$ \\
\hline \multicolumn{3}{|l|}{ Pleural Fluid IgA/lgG } \\
\hline (1:50)/ MT10.3:MPT64 (1:200) & $27(93.1)$ & $36(92.3)$ \\
\hline \multicolumn{3}{|l|}{ Pleural Fluid IgA } \\
\hline$(1: 50) / F 2(1: 50) / A D A$ & $28(96.6 \%)$ & $36(92.3 \%)$ \\
\hline
\end{tabular}

$O P L$ other non-tuberculous pleurisy

Boldface: represents the combinatory test results of best sensitivities and specificity

The present study provides a simpler alternative ELISA for ADA combination.

Notably, the better fused antigen MT10.3:MPT64 performance for PF IgA detection corroborates previous studies [10], although the lower reactivity on single antigens MT10.3 (20.7\%) and MPT64 (24.1\%) was not expected and is in disagreement with the previous report $(72 \%)$ assessing populations carrying similar pleurisy morbidities to the present study [33]. One explanation could be antigen degradation, as the batches used herein were old and underwent several freezing and thawing cycles. On the other hand, for serum, the present results corroborate those reported by Silva et al. [34] where, even evaluating pulmonary TB, both single antigens failed to show high sensitivity $(<34.5 \%)$. Nevertheless, reduced recognition of these antigens by serum IgA and IgG (including to PPE59) was also detected.

It is well known that IgA is a predominant mucosal/ serous immunoglobulin, also secreted in the pleural space $[35,36]$. However, IgA against mycobacterial Ags has been found in pulmonary TB patient sera by several authors [11, 37-40]. Zhao et al. [41] suggested Ab-based tests in plasma to identify Beijing MTB infection. In our study, IgG and IgA resulted in lower serum positivity compared to PF results, but the frequency of positive results is higher to that in microbiological tests, therefore useful in their absence and other, less sensitive, conventional PLTB diagnostic tests. The use of recombinant fused antigens in diagnostic tests constitutes an interesting strategy to increase accuracy and simplicity. However, fusion of different antigens may change reactivity 


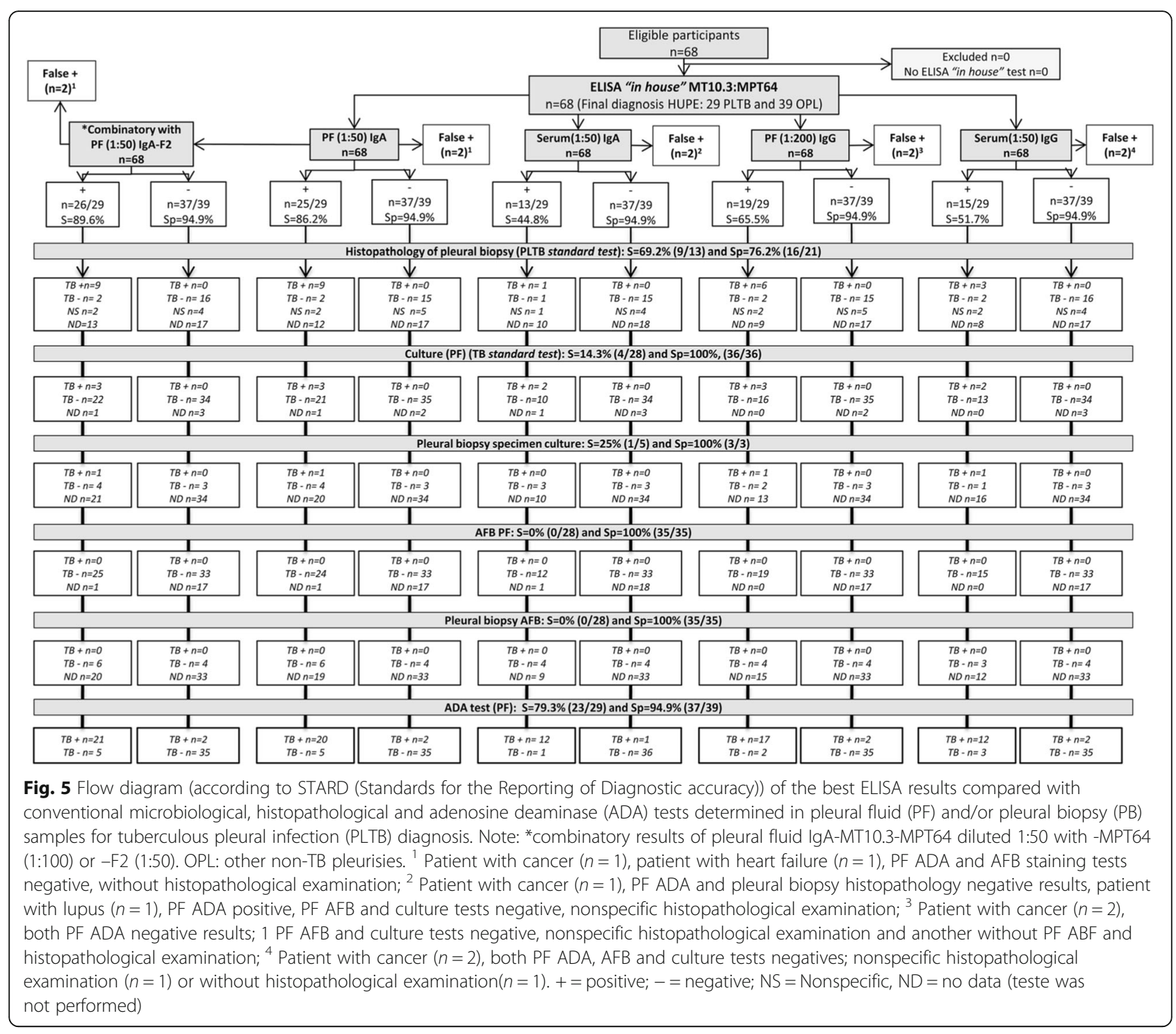

according to gene position in their construction $[10,11$, 42]. The higher sensitivity elicited by MT10.3:MPT64 may be related to this fact, since the fusion protein expressed by opposite genes according to that construction seems to display low stability and quality (personal communication).

As expected, histopathological examinations demonstrated higher sensitivity than the conventional microbiological methods for PLTB diagnosis, but lower compared to the developed ELISA. Nonetheless, among the patients with negative results or no information, the ELISA PF IgA-MT10.3:MPT64 was able to identify most PLTB patients, which could be supportive of the hypothesis that, in some cases, pleural effusion may also be caused by the possible entry of mycobacterial antigens into the pleural space, thereby stimulating the presence of IgA at this site [43]. Conversely, few OPL patients diagnosed by histopathology presented false-positive ELISA IgA-MT10.3:MPT64 results (1/16, 6.2\%).

The F2 (MT10.3(1M-40S):MPT64m ${ }_{(91 \mathrm{~L}-205 \mathrm{~A})}$ : MT10.3(415-96) $)$ containing peptides of both antigens led to decreased mean levels of reactivity to almost half among PLTB cases $(0.553 \pm 0.230)$, but no change for OPL cases $(0.351 \pm 0.212)$ compared to the full fused genes $(0.821 \pm 0.213$ or $0.387 \pm 0.188$, respectively). However, F2 recognition by a PLTB group added sensitivity to the combinatory of results using both fusion antigens for PF IgA detection. This may be explained by exposure of other epitopes not available in the full gene construction or single antigens.

Until now, no publications associating the F2 protein chimera or PPE59 in PF IgA detection in PLTB patient are available. Despite their lower sensitivity compared to MT10.3:MPT64, sensitivity was higher to that AFB 
smear exams. Among microbiological tests used for TB diagnosis, AFB is the flagship, as it is easy to apply, rapid and cheap, although exhibiting low sensitivity, nevertheless considering that the ELISA has the potential to be point of care (POC) test, similar results to those found in bacterioscopy assessments may be obtained quickly. Serum IgA-F2 elicited the best reactivity compared to the other antigens, detecting half of the PLTB cases (51.7\%); although in pulmonary $\mathrm{TB}$ this positivity was evidenced for IgG-F2 [11], a discrepancy which may be related to the different clinical TB forms. It is possible that the compliance of the fused protein, where the repositioning of the gene fragments led to the formation of new epitopes and, consequently, obfuscation of others, could positively affect IgA or IgG recognition in PL or pulmonary TB patient sera. The third single antigen used in this study, PPE59, performed similarly, at low reactivity for serum IgG in PLTB, as previously observed for pulmonary and different extrapulmonary TB cases (25 and $0 \%$, respectively) (unpublished data). However, a higher PF (1:100) IgA-PPE59 (62.1\%) sensitivity compared to that unpublished data (54 and $28 \%$, respectively) is described herein for the first time. To date, PPE59 it is known to induce cell-mediated response by IFN- $\gamma$ and interleukin-10 in pulmonary TB $[12,15]$ and, as a result of our study, immunodominance of PF IgA but non-IgG in PLTB patient. Therefore, PPE59 protein displays potential as specific TB diagnosis markers and may assist in the diagnostic investigations performed in PLTB.

Some Bacille Calmette Guérin (BCG) vaccine strains, including the one used in Brazil, contain the gene coding for the MPT64 antigen and it has been hypothesized that tumor cells and the BCG strain may share antigens $[10,44,45]$. In the present study, cross-reactivity was observed, as in previous similar studies [10, 26, 46, 47]. In our and in the other similar Brazilian [10] studies the majority of participants were BCG vaccinated and, more important, they live in a city with a high TB incidence rate $[48,49]$. Thus, it is possible the OPL patients may have presented TB as undiagnosed co-morbidity or were LTBI, since some of them presented QFT-GIT ${ }^{\oplus}$ positive results. Lupus autoimmune disorder based diagnostics rely solely on clinical examination, negative PF culture or AFB and positive for the ADA assay. Another possible explanation is that, $64 \%$ of OPL cases presented cancer and higher mean IgA levels in both PF and serum, as well as PF IgG, compared to other OPL cases. Falsepositive ELISA results in patients with lung cancer have been reported by other authors [33, 35].

This study has some limitations, such as: 1) in the absence of a precise diagnostic tests for PLTB and the limitations of the ADA, it is possible that patients were in some stage of TB status, including LTBI, but were mistakenly classified as OPL because not all the resources available for the TB diagnosis were applied, 2) patients recruitment was performed in a single healthcare center, which contributes to the limitation in the number of the cases included, 3) failure to follow the clinical evolution of the patients, which would make it possible to ascertain $\mathrm{TB}$ disease in false-positive cases in the tests proposed here.

\section{Conclusions}

A successful ELISA for the detection of IgA and IgG in body fluids of relative invasive power, such as PF and serum against different mycobacterial antigens for PLTB diagnosis was described. In addition, the MT10:MPT64 fusion protein was validated as highly promising marker in a new PLTB cohort, although presenting less sensitivity for IgG in serum, both with high specificity diagnostic potential. PPE59 as a single antigen recognized by PF and serum IgA at high sensibility and specificity compared to conventional microbiological assays was described for the first time. The combinatory results of PF (1:50) IgA MT-10:MPT64/-F2 performed better than conventional diagnostic tests, but their combination with ADA improved PLTB diagnostic, which may contribute to the adequate treatment to avoid PLTB evolution to tuberculous emphysema or pleural fibrosis. Finally, it is underway the development of a PF IgA- MT10.3: MPT64, -PPE59 or IgA MT-10:MPT64/F2 rapid diagnostic tool based on lateral flow as prove of concept.

\section{Methods}

\section{Study design, participants and ethical statement}

Observational, cross-sectional and prospective study where sera and PF samples from 68 individuals attended by spontaneous demand and diagnosed with PLTB or OPL at the Hospital Universitário Pedro Ernesto (HUPE)/UERJ, were collected from March 2015 to March 2017. The inclusion criterion was the presence of pleural effusion with clinical indication for thoracentesis, as described elsewhere [33]. All participants were $\geq 18$ years old. Exclusion criteria were, pregnant women, those who did not agree to participate or provide clinical specimens and those who refused to sign the informed consent form. The study population included: i) PLTB cases, presence of infectious clinical manifestations accompanied by ADA positivity ( $>40 \mathrm{U} / \mathrm{L}$ ), and/or positive acid-fast bacilli (AFB) staining and/or positive MTB culture in pleural fluid or tissue; and/or by granuloma findings in histopathological pleural tissue tests; and/or cytopathological PF investigations indicating lymphocytic exudate without malignity; and/or diagnosed with clinical findings, such as fever, night sweats, lymphocytic exudative pleural effusion with a non-diagnostic pleural biopsy (with either positive or negative culture), and a good response to specific treatment; and ii) OPL cases, 
with diagnosis based on clinical manifestations accompanied by histopathological pleura examinations and PF cytopathology, compatible with pleurisy other than TB. Most patients presented information regarding BCG vaccinations (62/68). PF samples underwent the ADA test based on Giusti's method [50], at the Hermes Pardini Laboratory. Human immunodeficiency virus (HIV) infection status was determined in sera using the Cobas ${ }^{\circ}$, chemiluminescence test (Roche Molecular Systems Inc., CA, USA). Pleural tissue for biopsies and PF samples underwent AFB staining and culture in LowensteinJensen's (LJ) medium, according to routine laboratory methods. Pleural biopsy fragments were taken for histopathological examinations and $\mathrm{PF}$, for cytopathological investigations. This study was approved by the HUPE/ UERJ Ethics Committee, no. 1.100.772. Sample donation was obtained only after written informed consent of all participants. Clinical, laboratory, and demographic data were obtained from medical records.

\section{Test methods}

\section{Clinical specimens and sample processing}

Venous blood was collected in $10 \mathrm{~mL}$ vacutainer tubes (BD Biosciences, Mountain View, CA) and PF was collected in $50 \mathrm{~mL}$ conical Falcon tubes at the time of diagnosis, and immediately processed. Samples were centrifuged at $930 \mathrm{x} \mathrm{g}$ for $10 \mathrm{~min}$, at $25^{\circ} \mathrm{C}$ for serum or $4{ }^{\circ} \mathrm{C}$ for PF. Supernatant aliquots were then stored at $80^{\circ} \mathrm{C}$ until use. PF or sera samples with notable hemolysis were excluded from the study. All procedures follow international biosecurity standards.

\section{Antigens}

The recombinant fused antigens MT10.3:MPT64, F2 $\left(\mathrm{MT10.3}{ }_{(1 \mathrm{M}-40 \mathrm{~S})}:\right.$ MPT64m(91L-205A):MT10.3 $\left.{ }_{(41 \mathrm{~S}-96)}\right)$, and PPE59 were engineered in our laboratory, as described elsewhere $[10,11,16]$. LIONEX Diagnostics \& Therapeutics $\mathrm{GmbH}$ (Braunschweig, Germany) kindly donated Ags MT10.3 and MPT64.

\section{$\lg A$ and IgG "in house "enzyme immunosorbent assay (ELISA)}

Flat-bottom polystyrene microtiter plates (Maxisorp; Nunc, Swedesboro, NJ, USA) were coated and incubated for $2 \mathrm{~h}$ at $37^{\circ} \mathrm{C}$ with $50 \mu \mathrm{L} /$ well of an antigen solution in carbonate-bicarbonate buffer (CBB, pH 9.6), at concentrations previously determined. The plates were washed three times with $200 \mu \mathrm{L}$ of phosphate buffered saline with $0.01 \%$ tween 20 (PBSt) $\mathrm{pH}=7.4$ and blocked by adding $100 \mu \mathrm{L} /$ well of $5 \%$ bovine serum albumin in PBSt (BSA-PBSt) and incubated, as described above. After washing, the plates were immediately used or stored at $4{ }^{\circ} \mathrm{C}$ (> 2 weeks). Each $50 \mu \mathrm{L}$ of serial 2 -fold dilutions of PF or sera samples in $1 \%$ BSA-PBSt were added to the respective wells and incubated for $1 \mathrm{~h}$ at $37^{\circ} \mathrm{C}$. After being washed, new incubation on $50 \mu \mathrm{L}$ solution of horseradish peroxidase-conjugated goat anti-human IgA or IgG monoclonal antibodies (HRP, Pierce, Rockford, IL) at different dilutions in 1\% BSA-PBSt was used. After a final washing, HRP activity was detected adding $50 \mu \mathrm{L} /$ well of the chromogenic 3.3,5.5-tetramethylbenzidine substrate solution (TMB; Pierce, Rockford, IL), and leaving the plate for $20 \mathrm{~min}$ in the dark at room temperature. To stop the reactions, $50 \mu \mathrm{L} /$ well of $2 \mathrm{~mol}$. $\mathrm{L}^{-1}$ sulfuric acid was added and the absorbance was read at $450 \mathrm{~nm}$. All tests were performed in duplicate, and, pooled positive and negative controls (dilution previously determined) were used as references in each set of experiments. To estimate IgG-MT10.3:MPT64 immunoreactivity, the same procedure was used, with minor modification. The washings, dilutions of the samples and conjugates carried out, respectively, with PBSt $0.1 \%$, and PBSt $0.1 \%$ plus 0.3 mol. $\mathrm{L}^{-1} \mathrm{NaCl}$ as suggested by Araujo et al. [10]. An Additional file 2: Table S2 file exhibits the antigen, sample and conjugate standardizations and parameterizations for the ELISA tests.

\section{Statistical analyses}

M. tuberculosis protein immunoreactivity was determined by optical density (OD). Results are expressed as means \pm standard deviation (SD), and groups were compared using the Mann-Whitney or Kruskal-Wallis test. The chosen cutoff value was calculated for each antigen according to a receiver operating characteristic (ROC) curve analysis for each PF and serum dilution, fixing specificity at 95\%, based on all PLTB and OPL subjects. The diagnostic value of the ELISA was evaluated in terms of sensitivity $(\mathrm{S})$ and specificity $(\mathrm{Sp})$. A $p$ value $(p)$ of $\leq 0.05$ was considered statistically significant. A combinatory analysis of the results of the different proteins with test results used for routine diagnosis was carried out. Statistical analyses were performed using the Statistical Package for Social Sciences (SPSS) v. 20 (SPSS Inc., Chicago, IL) and Prism6 (Graph-Pad Software Inc., San Diego, CA) software.

\section{Supplementary information}

Supplementary information accompanies this paper at https://doi.org/10. 1186/s12865-019-0315-y.

\footnotetext{
Additional file 1: Table S1. Clinical and socioeconomic data of participants presenting pleural tuberculosis (PLTB) or non-TB pleural diseases (OPL). Supplementary Table S1 depicts the main clinical, laboratory, and epidemiological data of participants enrolled in this study. Note this table: ${ }^{*} p<0.05$. SD - Standard Deviation.1 ADA - adenosine deaminase cutoff of $>40 \mathrm{U} / \mathrm{L}, \mathrm{PL}-\mathrm{TB}$ : pleural tuberculosis patients; OPL: patients with others non-TB pleural diseases. SLE: Systemic lupus erythematosus. Note: In Brazil, pardo (brown) means a mixture of European, Black and Amerindian.
} 
Additional file 2: Table S2. The standardizations and parameterizations of antigens concentration, samples and conjugates dilutions for the $\lg \mathrm{A}$ and IgG ELISA detection in pleural fluid (PF) and serum of pleural tuberculosis (PLTB) and other pleurisy non TB (OPL). An Supplementary Table $\mathrm{S} 1$ exhibits the antigen, sample and conjugate standardizations and parameterizations for the ELISA tests. Note this table: X: represent the ELISA not possible parameters in the standardization.

\section{Abbreviations}

Ab: Antibody; ADA: Adenosine deaminase; AFB: Acid-Fast Bacilli stain; Ags: Antigens; BCG: Bacille Calmette Guérin; BSA: Bovine serum albumin; C: graus Celsius; CBB: Carbonate-bicarbonate buffer; CNPq: Conselho Nacional de Desenvolvimento Científico e Tecnológico; ELISA: Enzyme-liked ImunoSorbent Assay; F2: protein chimera MT10.3(1 M-40S):MPT64M(91 L205A):MT10.3(41S-96)); FAPERJ: Fundação de Amparo à Pesquisa do Estado do Rio de Janeiro; FIOCRUZ: Oswaldo Cruz institution; h: hours; HIV: Human immunodeficiency virus; HUPE: Hospital Universitário Pedro Ernesto; IFN: Interferon-gamma; IgA: Immunoglobulin A; IgG: Immunoglobulin G; LIP: Laboratório de Imunopatologia; L: Lowenstein-Jensen's medium; LTBI: Latent tuberculosis infection; ml: milliliter; MPT64 (Rv1980c): MTB antigen $(24 \mathrm{kDa}$ ) encoded by genes of the difference region 2; MT10.3 (ES6.9, TB10.3, Rv3019c): MTB antigen (10 kDa) encoded by genes of the difference region 2; MT10.3:MPT64: MTB antigens fusion MT10.3 and MPT64; MTB: Mycobacterium tuberculosis; NaCl: sodium chloride; nm: nanometer; OD: Optical density; OPL: Other non-tuberculous pleurisy; p: p valor; PBSt: Phosphatebuffered saline with tween; PF: Pleural fluid; PLTB: Pleural tuberculosis; POC: Point of care test; PPE59: MTB antigens encoded by RD11. PE (Pro-Glu) e PPE (Pro-Pro-Glu) Family; Prism6: Prism Graph-Pad Software; QFT-GIT: QuantiFERON-TB Gold In-Tube assay; RJ: Rio de Janeiro; ROC: Receiver operating characteristic; S: Sensitivity; SD: Standard deviations; Sp: Specificity; SPSS: Statistical Package for Social Sciences software; TB: Tuberculosis; TMB: 3,3,5,5-tetramethylbenzidine substrate solution; UERJ: Universidade Estadual do Rio de Janeiro; x g: g Force; $\mu$ l: microliter

\section{Acknowledgements}

This study was supported by Fundação de Amparo à Pesquisa do Estado do Rio de Janeiro (FAPERJ), Conselho Nacional de Desenvolvimento Científico e Tecnológico (CNPq), and FioTB network Instituto Oswaldo Cruz/Fundação Oswaldo Cruz, The authors would like to thank all professionals at HUPE whose collaboration allowed this study, as well as all those who participated in the study.

\section{Authors' contributions}

RJS conducted immunological experiments in the laboratory; analyzed and interpreted all patient data, and was a major contributor in writing the manuscript. RSC contributed to the recruitment and collection of samples of participant groups at HUPE, belonging to the Universidade do Estado do Rio de Janeiro. Was also responsible for processing and sending the samples to Laboratório de Microbiologia Celular. Contributed with collected patient data. IGS contributed with immunological experiments, and analyzed and interpreted all patient data. ACPM contributed by analyzing and interpreting all patient data. TTM contributed by performing thoracentesis and collecting the samples of participant groups at the HUPE, belonging to Universidade do Estado do Rio de Janeiro. APS contributed to recruitment of participant groups at the HUPE, belonging to Universidade do Estado do Rio de Janeiro, and was also responsible for the clinical, laboratory, and demographic data, and for updating the patient database from medical records. RR coordinated the Pulmonary and Tisiology Service at at the HUPE, belonging to Universidade do Estado do Rio de Janeiro. LSR coordinated the recruitment and collection of participant groups samples at the HUPE, belonging to Universidade do Estado do Rio de Janeiro; coordinated sending the samples from LIP to Laboratório de Microbiologia Celular, and coordinated patient data collection. In addition, also contributed in writing the manuscript. MHFS coordinated the project and immunological experiments at the Laboratório de Microbiologia Celular (IOC/FIOCRUZ), analyzed and interpreted all patient data and was a major contributor in writing the manuscript. All authors read and approved the final manuscript.

\section{Funding}

The supportive funding from Fundação de Amparo à Pesquisa do Estado do Rio de Janeiro (FAPERJ), the Conselho Nacional de Desenvolvimento Científico e Tecnológico (CNPq), and the FioTB network Instituto Oswaldo Cruz/Fundação Oswaldo Cruz were applied in purchase reagents for cloning, expression and purification of the antigens, purchase of all disposable and antibodies used in all phases of the study and transportation of patients' samples, respectively.

\section{Availability of data and materials}

The dataset that support the findings of this study are available from the authors but restrictions apply to the availability of these data, which were used under license for the current study and so are not publicly available. Data are however available from the corresponding author upon reasonable request.

\section{Ethics approval and consent to participate}

This study was approved by the Hospital Universitário Pedro Ernesto HUPE/UERJ Ethics Committee, number: 1.100.772. All procedures performed in studies involving human participants were in accordance with the ethical standards of the institutional and/or national research committee and with the 1964 Helsinki declaration and its later amendments or comparable ethical standards. Written informed consent was obtained from all individual participants included in this study.

\section{Consent for publication}

Not applicable.

\section{Competing interests}

The authors declare that they have no competing interests.

\section{Author details}

${ }^{1}$ Laboratorio de Microbiologia Celular, Instituto Oswaldo Cruz (IOC) Fundação Oswaldo Cruz (FIOCRUZ), Av. Brazil, 4365, Rio de Janeiro 21040-360, Brazil. ² Laboratório de Immunopatologia (LIP), Faculdade de Ciências Médicas, Universidade do Estado do Rio de Janeiro (UERJ), Rio de Janeiro, RJ, Brazil. ${ }^{3}$ Serviço de Pneumologia e Tisiologia, Hospital Universitário Pedro Ernesto (HUPE)/UERJ, Rio de Janeiro, RJ, Brazil.

Received: 4 December 2018 Accepted: 9 September 2019

Published online: 17 October 2019

\section{References}

1. Light RW. Update on tuberculous pleural effusion. Respirology. 2010. https://doi.org/10.1111/j.1440-1843.2010.01723.x.

2. Dong $X$, Yang J. High IL-35 pleural expression in patients with tuberculous pleural effusion. Med Sci Monit. 2015. https://doi.org/10.12659/MSM.892562.

3. WHO Report: World Health Organization. Global Tuberculosis Report 2017, vol. 249. Geneva: World Health Organization; 2017. https://apps.who.int/iris/ handle/10665/259366. Accessed 20 Nov 2018

4. Neves DD, Dias RM, Cunha AJ. Predictive model for the diagnosis of tuberculous pleural effusion. Braz J Infect Dis. 2007. https://doi.org/10.1590/ S1413-86702007000100019

5. Sales RK, Vargas FS, Capelozz VL, Seiscento M, Genofre EH, Teixeira LR, Antonangelo L. Predictive models for diagnosis of pleural effusions secondary to tuberculosis or cancer. Respirology. 2009. https://doi.org/10. 1111/j.1440-1843.2009.01621.x

6. Candela A, Andujar J, Hernández L, Martín C, Barroso E, Arriero JM, Romero S. Functional sequelae of tuberculous pleurisy in patients correctly treated. Chest. 2003. https://doi.org/10.1378/chest.123.6.1996

7. Sonmezoglu Y, Turna A, Cevik A, Demir A, Sayar A, Dincer Y, Bedirhan MA, Gurses A. Factors affecting morbidity in chronic tuberculous empyema. Thorac Cardiovasc Surg. 2008. https://doi.org/10.1055/s-2007-965301

8. Kataria YP, Khurshid I. Adenosine deaminase in the diagnosis of tuberculous pleural effusion. Chest. 2001. https://doi.org/10.1378/chest.120.2.334

9. Morisson P, Neves DD. Avaliação da adenosina desaminase no diagnóstico da tuberculose pleural: uma metanálise brasileira. J Bras Pneumol. 2008. https://doi.org/10.1590/S1806-37132008000400006

10. Araujo LS, Maciel RM, Trajman A, Saad MH. Assessment of the IgA immunoassay diagnostic potential of the Mycobacterium tuberculosis MT10. 
3-MPT64 fusion protein in tuberculous pleural fluid. Clin Vaccine Immunol. 2010. https://doi.org/10.1128/CVI.00372-10

11. Sardella IG, Mulinari ACP, Fonseca LS, Saad MHF. Cloning, expression and characterization of fusion proteins based on peptides of Rv1980c disrupting Rv3019c sequence and evaluation of its potential immunoreactivity in pulmonary tuberculosis sera. Mycobact Disv. 2015. https://doi.org/10.4172/ 2161-1068.1000183

12. Cole ST, Barrell BG. Analysis of the genome of Mycobacterium tuberculosis H37Rv. Novartis Found Symp. 1998. https://doi.org/10.1002/0470846526. ch12 (discussion 172-167).

13. Al-Attiyah R, Mustafa AS. Characterization of human cellular immune responses to novel Mycobacterium tuberculosis antigens encoded by genomic regions absent in Mycobacterium bovis BCG. Infect Immun. 2008 https://doi.org/10.1128/IAl.00199-08

14. Karboul A, Mazza A, Gey Van Pittius NC, Ho JL, Brousseau R, Mardass IH. Frequent homologous recombination events in Mycobacterium tuberculosis PE/PPE multigene families: potential role in antigenic variability. J Bacteriol. 2008. https://doi.org/10.1128/JB.00827-08

15. Chen J, Su X, Zhang Y, Wang S, Shao L, Wu J, Wang F, Zhang S, Wang J, Weng $X$, Wang $H$, Zhang W. Novel recombinant RD2- and RD11-encoded Mycobacterium tuberculosis antigens are potential candidates for diagnosis of tuberculosis infections in BCG-vaccinated individuals. Microbes Infect. 2009. https://doi.org/10.1016/j.micinf.2009.05.008

16. Mulinari ACP. Obtenção da proteína codificada pelo gene RV3429 de Mycobacterium tuberculosis e avaliação da reatividade imune humoral. Masters Dissertation. Rio de Janeiro: Fundação Oswaldo Cruz; 2016. https:// www.arca.fiocruz.br/handle/icict/22982

17. Meyer TF, Gibbs CP, Haas R. Variation and control of protein expression in Neisseria. Annu Rev Microbiol. 1990;44:451-77.

18. Dheda K, Van Zyl-Smit RN, Sechi LA, Badri M, Meldau R, Meldau S, Symons G, Semple PL, Maredza A, Dawson R, Wainwright H, Whitelaw A, Vallie Y, Raubenheime RP, Bateman ED, Zumla A. Utility of quantitative T-cell responses versus unstimulated interferon-\{gamma\} for the diagnosis of pleural tuberculosis. Eur Respir J. 2009. https://doi.org/10.1183/09031936. 00005309

19. Li M, Wang H, Wang X, Huang J, Wang J, Xi X. Diagnostic accuracy of tumor necrosis factor-alpha, interferon-gamma, interleukin-10 and adenosine deaminase 2 in differential diagnosis between tuberculous pleural effusion and malignant pleural effusion. J Cardiothorac Surg. 2014. https://doi.org/10. 1186/1749-8090-9-118

20. Shu CC, Wang JY, Hsu CL, Keng LT, Tsui K, Lin JF, Lai HC, Yu CJ, Lee LN, Luh $K T$. Diagnostic role of inflammatory and anti-inflammatory cytokines and effector molecules of cytotoxic T lymphocytes in tuberculous pleural effusion. Respirology. 2015. https://doi.org/10.1111/resp.12414

21. Trajman A, Kaisermann C, Luiz RR, Sperhacke RD, Rossetti ML, Saad MHF, Sardella IG, Spector N, Kritsk AL. Pleural fluid ADA, IgA-ELISA and PCR sensitivities for the diagnosis of pleural tuberculosis. Scand J Clin Lab Invest. 2007. https://doi.org/10.1080/00365510701459742

22. Ogata Y, Aoe K, Hiraki A, Murakami K, Kishino D, Chikamori K, Maeda T, Ueoka H, Kiura K, Tanimoto M. Is adenosine deaminase in pleural fluid a useful marker for differentiating tuberculosis from lung cancer or mesothelioma in Japan, a country with intermediate incidence of tuberculosis? Acta Med Okayama. 2011. https://doi.org/10.18926/AMO/ 46851.

23. Kashiwabara K, Okamoto T, Yamane $\mathrm{H}$. When pleural potassium exceeds 5.0 $\mathrm{mEq} / \mathrm{L}$, high pleural adenosine deaminase levels do not necessarily indicate tuberculous pleuritis. Respirology. 2012. https://doi.org/10.1111/j.1440-1843. 2011.02053.x.

24. Tyagi S, Sharma N, Tyagi JS, Haldar S. Challenges in pleural tuberculosis diagnosis: existing reference standards and nucleic acid tests. Future Microbiol. 2017. https://doi.org/10.2217/fmb-2017-0028.

25. Santos AP, Corrêa RDS, Ribeiro-Alves M, Soares da Silva ACO, Mafort TT, Leung J, Pereira GMB, Rodrigues LS, Rufino R. Application of Venn's diagram in the diagnosis of pleural tuberculosis using IFN- $\gamma$, IP-10 and adenosine deaminase. PLoS One. 2018. https://doi.org/10.1371/journal.pone.0202481.

26. Samanich $\mathrm{K}$, Belisle JT, Laal S. Homogeneity of antibody responses in tuberculosis patients. Infect Immun. 2001. https://doi.org/10.1128/IAl.69.7. 4600-4609.2001

27. Abebe F, Holm-Hansen C, Wiker HG, Bjune G. Progress in serodiagnosis of Mycobacterium tuberculosis infection. Scand J Immunol. 2007. https://doi. org/10.1111/j.1365-3083.2007.01978.x
28. Pathakumari B, Prabhavathi M, Anbarasu D, Paramanandhan P, Raja A. Dynamic lgG antibody response to immunodominant antigens of $M$. tuberculosis for active TB diagnosis in high endemic settings. Clin Chim Acta. 2016. https://doi.org/10.1016/j.cca.2016.06.033.

29. He Y, Zhang W, Huang T, Wang X, Wang M. Evaluation of a diagnostic flow chart applying medical thoracoscopy, adenosine deaminase and T-SPOT.TB in diagnosis of tuberculous pleural effusion. Eur Rev Med Pharmacol Sci. 2015;19:3563-8

30. Li D, Shen Y, Fu X, Li M, Wang T, Wen F. Combined detections of interleukin-33 and adenosine deaminase for diagnosis of tuberculous pleural effusion. Int J Clin Exp Pathol. 2015;1:888-93.

31. Kim MC, Kim SM, Lee SO, Choi SH, Kim YS, Woo JH, Kim SH. A diagnostic algorithm for tuberculous pleurisy using the ELISPOT assay on peripheral blood and pleural effusion. Infect Dis (Lond). 2016. https://doi.org/10.1080/ 23744235.2016 .1183816

32. Liu Y, Ou Q, Zheng J, Shen L, Zhang B, Weng X, Shao L, Gao Y, Zhang W. A combination of the QuantiFERON-TB gold in-tube assay and the detection of adenosine deaminase improves the diagnosis of tuberculous pleural effusion. Emerg Microbes Infect. 2016. https://doi.org/10.1038/emi.2016.80

33. Kaisermann M, Sardella IG, Jonas F, Kampfer S, Singh M, Trajmann A, Saad MHF. IgA response to Mycobacterium tuberculosis recombinants MPT64 e MT-10.3 antigens in fluid pleural of patients with tubeculous pleurisy. Int J Tuberc Lung Dis. 2005;9(4):461-6.

34. Silva VM, Sardella IG, Luiz RR, Cunha AJ, Cavalcanti AH, Mahavir S, Barreto MM, Rodrigues RS, Carvalho TF, Saad MH. Immunoreactivity of five antigens of Mycobacterium tuberculosis in patients attending a public health care facility in an area with high endemicity for TB. Microbiol Immunol. 2008. https://doi.org/10.1111/j.1348-0421.2008.00072.x

35. Van Vooren JP, Farber CM, De Bruyn J, Yernault JC. Antimycobacterial antibodies in pleural effusions. Chest. 1990. https:/doi.org/10.1378/chest.97.1.88

36. Parslow TG. Immunoglobulins \& immunoglobulin genes. In: Stites DP, Terr Al, Parslow TG, editors. Medical Immunology. 9th ed. Stamford: Appleton \& Lange; 1997. p. 102-42.

37. Schuler NW, Rom WN. The host immune response to tuberculosis. Am J Respir Crit Care Med. 1998. https://doi.org/10.1164/ajrccm.157.3. 9708002

38. Wilsher ML, Hagan C, Prestidge R, Wells AU, Murison G. Human in vitro immune response to Mycobacterium tuberculosis. Tuberc Lung Dis. 1999. https://doi.org/10.1054/tuld.1999.0223

39. Glatman-Freedman A. Advantages in antibody-mediated immunity against Mycobacterium tuberculosis: implications for a novel vaccine strategy. FEMS Immunol Med Microbiol. 2003. https://doi.org/10.1016/509288244(03)00172-X.

40. Bezerra JM, Beck ST, Kanunfre KA, Leite OM, Ferreira AW. A study of IgA antibody response to different Mycobacterium tuberculosis antigens in the diagnosis and monitoring of pulmonary tuberculosis. Braz J Infect Dis. 2009. https://doi.org/10.1590/S1413-86702009000100012

41. Zhao J, Shiratori B, Okumura M, Yanai H, Matsumoto M, Nakajima C, Mizuno K, Ono K, Oda T, Chagan-Yasutan H, Ashino Y, Matsuba T, Yoshiyama T, Suzuki Y, Hattori T. Difference in antibody responses to Mycobacterium tuberculosis antigens in Japanese tuberculosis patients infected with the Beijing/non-Beijing genotype. J Immunol Res. 2017. https://doi.org/10.1155/ 2017/4797856

42. Hoff ST, Abebe M, Ravn P, Range N, Malenganisho W, Rodriques DS, Kallas EG, Søborg C, Mark Doherty T, Andersen P, Weldingh K. Evaluation of Mycobacterium tuberculosis--specific antibody responses in populations with different levels of exposure from Tanzania, Ethiopia, Brazil, and Denmark. Clin Infect Dis. 2007. https://doi.org/10.1086/520662

43. Seiscento M, Conde MB, Dalcolmo MMP. Tuberculose Pleural. J Bras Pneumol. 2006;32(Sulp 4):S174-81. https://doi.org/10.1590/S180637132006000900003

44. Minden P, Jarrett C, Mcclatchy JK, Gutterman JU, Hersh EM. Antibodies to melanoma cell and BCG antigens in sera from tumourfree individuals and from melanoma patients. Nature. 1976. https://doi.org/10.1038/263774a0

45. Maver C, Kausel C, Lininger L, Mckneally M. Intrapleural BCG immunotherapy of lung cancer patients. Recent Results Cancer Res. 1982. https://doi.org/10.1007/978-3-642-81685-7_36

46. Dhand R, Ganguly NK, Vaishnavi C, Gilhotra R, Malik SK. False-positive reactions with enzyme-linked immunosorbent assay of Mycobacterium tuberculosis antigens in pleural fluid. J Med Microbiol. 1988. https://doi.org/ 10.1099/00222615-26-4-241. 
47. She RC, Litwin CM. Performance of a tuberculosis serologic assay in various patient populations. Am J Clin Pathol. 2015. https://doi.org/10.1309/ AJCP22DBRYZQGRBI.

48. Oliveira GP, Torrens AW, Bartholomay P, Barreira D. Tuberculosis in Brazil: last ten years analysis - 2001-2010. Braz J Infect Dis. 2013. https://doi.org/ 10.1016/j.bjid.2013.01.005

49. Rodrigues NCP, Andrade MKN, O'Dwyer G, Flynn M, Braga JU, Almeida AS, Bastos LS, Lino VTS. Distribution of pulmonary tuberculosis in Rio de Janeiro (Brazil): a spatial analysis. Cien Saude Colet. 2017. https://doi.org/10.1590/ 1413-812320172212.0143016

50. Giusti G, Galanti B. Methods of enzymatic analysis. Weinheim: VerlagChemie; 1984. p. 315.

\section{Publisher's Note}

Springer Nature remains neutral with regard to jurisdictional claims in published maps and institutional affiliations.

Ready to submit your research? Choose BMC and benefit from:

- fast, convenient online submission

- thorough peer review by experienced researchers in your field

- rapid publication on acceptance

- support for research data, including large and complex data types

- gold Open Access which fosters wider collaboration and increased citations

- maximum visibility for your research: over $100 \mathrm{M}$ website views per year

At $\mathrm{BMC}$, research is always in progress.

Learn more biomedcentral.com/submissions 